Revista Brasileira

de Estudos de

Cinema

e Audiovisual

\title{
A segunda fase da conversão para o cinema sonoro no Rio de Janeiro (1929-1930)
}

Rafael de Luna Freire ${ }^{1}$

1 Professor no Departamento de Cinema e Vídeo e no Programa de PósGraduação em Comunicação da Universidade Federal Fluminense. Desenvolve pesquisas sobre a história do cinema brasileiro e vem publicando diversos artigos sobre o processo de conversão para o cinema sonoro no Brasil. e-mail: rafaeldeluna@hotmail.com 


\section{Resumo}

Este artigo define e analisa a segunda fase da conversão para o cinema sonoro na cidade do Rio de Janeiro, entre outubro de 1929 e dezembro de 1930. Entendemos esse processo como a adaptação do circuito cinematográfico exibidor carioca para a projeção de filmes sincronizados. São discutidas as principais características dessa segunda fase, quando a nova tecnologia se espalhou por diferentes regiões da cidade, atingindo salas de cinema mais populares e consolidando o novo formato de exibição junto ao público carioca.

Palavras-chave: Filme sonoro; Exibição; Salas de cinema; Rio de Janeiro.

\section{Abstract}

This article defines and analyzes the second phase of the conversion to sound cinema in the city of Rio de Janeiro, between October 1929 and December 1930. We understand this process as the adaptation of the Rio film exhibition circuit for the projection of synchronized movies. The article discusses the main features of this second phase, when the new technology spread to different areas of the city, reaching more popular movie theaters and consolidating the new technology to the "carioca" public.

Keywords: Sound film; Exhibition; Movie theaters; Rio de Janeiro. 


\section{Introdução}

No artigo Toward a Historiography of American Film, publicado em 1977, o pesquisador Charles F. Altman - que posteriormente passaria a assinar como Rick Altman - questionava as mais frequentes abordagens sobre a história do cinema norte-americano. Um dos problemas identificado pelo autor era referente à noção de periodização, uma vez que os períodos e critérios utilizados pelos livros e estudos então disponíveis eram frequentemente importados acriticamente da história política ou literária para a história do cinema, sem perceber, porém, os ritmos diferentes entre um e outro. Escrevia Altman:

\footnotetext{
Dada a escala miniaturizada da história do cinema, nós devemos ser particularmente cuidadosos com os meses, e mais ainda com os anos, devendo resistir à tentação de confundir periodizações retiradas da própria história do cinema com aquelas emprestadas dos determinantes sociais do cinema. (ALTMAN, 1977, p. 13). ${ }^{2}$
}

Publicado no ano anterior à Conferência da Federação Internacional de Filmes (FIAF), em Brighton, Inglaterra, em 1978 - marco do que viria a ser chamada de Nova História do Cinema (New Film History) ${ }^{3}$-, o artigo de Altman é bastante crítico sobre a bibliografia então existente sobre a história do cinema nos EUA, sugerindo novas metodologias, abordagens e temas. Um dos mais promissores caminhos dessa nova historiografia serão os estudos sobre a recepção, com particular atenção aos espaços de exibição dos filmes. Robert C. Allen e Douglas Gomery (1985), dois dos principais representantes dessa história revisionista do cinema, vão destacar a importância dos estudos locais de recepção, tanto diante do desconhecimento que ainda grassava sobre o tema, quanto pelas possibilidades de novas informações, questionamentos e proposições que eles traziam.

\footnotetext{
2 "Given the micro-miniaturized scale of film history, we must be particularly careful with months, let alone years, and must resist the temptation to confuse periodizations derived from film's internal history with those borrowed from film's social determinant". (Tradução do autor).

${ }^{3}$ Sobre a Nova História do Cinema, ver o artigo escrito no calor do momento por Thomas Elsaesser. (1986).
} 
Em relação ao cinema brasileiro, o impacto do renovado vigor dos estudos históricos sobre cinema - baseado no trabalho conjunto com cinematecas, na ampliação de fontes, e no maior rigor nas abordagens - também tem sido sentido com cada vez mais intensidade nos últimos anos. Alinhado a essa perspectiva e tomando como tema a conversão para o cinema sonoro no Brasil, o presente trabalho busca aplicar a esse objeto duas das considerações expostas nos parágrafos anteriores: a criação de uma periodização específica ao processo histórico do cinema e a atenção especial às condições históricas de recepção.

Portanto, como já dito, esse artigo faz parte de um projeto de pesquisa mais amplo que investiga a conversão para o cinema sonoro no Brasil, aqui entendida como o gradual processo de adoção, como padrão comercial das salas de exibição, da programação e projeção de filmes com acompanhamento sonoro sincronizado e reproduzido mecanicamente. Para analisar esse processo histórico em sua evidente complexidade - destacando a existência de ritmos desiguais de seu desenvolvimento em diferentes cidades e regiões do Brasil -, optamos por uma delimitação temporal e espacial mais restrita.

Assim, o presente texto propõe um recorte bastante preciso: a análise da conversão do circuito exibidor da cidade do Rio de Janeiro num período de cerca de quinze meses, entre outubro de 1929 e dezembro de 1930. Acreditamos que esse momento pode ser caracterizado como a segunda fase de conversão para o cinema sonoro na então Capital Federal.

\section{A primeira fase: junho a setembro de 1929.}

Em outro trabalho, abordei o que eu defini como a primeira fase de conversão para o cinema sonoro do circuito exibidor da cidade do Rio de Janeiro (FREIRE, 2012a). Esta teve início com a primeira exibição de um filme sonoro nos modernos sistemas Vitaphone (som em disco) e Movietone (som no filme), no recémreformado cinema Palácio Theatro, em 20 de junho de 1929, com a exibição do filme musicado, cantado e "100\% falado" A melodia da Broadway (Broadway Melody, Harry Beaumont, 1929). 
Durante essa primeira fase, ocorrida entre junho e setembro de 1929, os jornais cariocas alardeavam a "febre dos sincronizados" que atingia a cidade. A imprensa registrou o sucesso da novidade, marcado pelos recordes de bilheteria e pelas longas filas nos cinemas já convertidos para a projeção sonora, com público de maior poder aquisitivo indo ver e ouvir mais de uma vez os novos e afamados talkies (de talking pictures).

A principal característica dessa fase inicial foi o fato da conversão ter abarcado somente os grandes palácios de cinema da Cinelândia. Estas salas de exibição eram as melhores e mais luxuosas da cidade e foram responsáveis pelo lançamento, na então Capital Federal dos primeiros filmes cantados, musicados e/ou falados, de cada um dos principais estúdios norte-americanos. Durante esse momento de enorme popularidade dos novos filmes sincronizados, chegou a ocorrer, inclusive, uma disputa entre as agências distribuidoras por espaço na programação dos então poucos cinemas já convertidos. A concorrência inicial era tão grande ao ponto de duas salas de diferentes arrendatários, tais como o cine Glória e o cine Império, localizadas lado a lado na Praça Floriano, inaugurarem seus equipamentos sonoros exatamente no mesmo $\mathrm{dia}^{4}$.

Outras características comuns a essas salas de cinema pioneiras na exibição de longas-metragens sonoros no Rio de Janeiro eram a elevação no preço dos ingressos - o mais caro chegaria a custar cinco mil réis - e o fato de todos os cinemas terem adquirido os dispendiosos equipamentos sonoros Western Electric. Importados dos Estados Unidos, estes eram tidos como os melhores aparelhos da época, sendo conjugados para os sistemas Vitaphone e Movietone.

Com uma duração de apenas quatro meses, essa primeira fase foi marcada,

\footnotetext{
${ }^{4}$ Uma analogia interessante pode ser feita com o cenário recente do mercado exibidor nacional, marcado pela grande oferta de títulos em 3-D digital, mas relativamente poucas salas aparelhadas para esse tipo de projeção. O resultado desse desequilíbrio implicava em: 1) necessidade de alguns títulos terem de aguardar datas na grade de programação das salas adaptadas para estrearem (ficando na "prateleira"); 2) a grande rotatividade de filmes nas salas aparelhadas, com mais de um título sendo exibido em horários distintos; 3) a redução do tempo de permanência dos filmes em cartaz quando não atingem bilheterias expressivas.
} 
portanto, pela rápida conversão das seis melhores salas de cinema do Rio de Janeiro, todas localizadas a poucos metros uma das outras. Além de luxuosas, eram salas amplas - com lotação média superior a 1.000 poltronas - e, portanto, potencialmente lucrativas, mesmo diante do grande investimento necessário. Além disso, todas eram salas de exibição novas e modernas, com no máximo quatro anos de existência ${ }^{5}$. Esses seis cinemas eram explorados por três das principais companhias exibidoras atuantes na cidade: a Companhia Brasil Cinematográfica - CBC, de Francisco Serrador (Palácio Theatro, Odeon e Glória), a Marc Ferrez \& Filhos (Pathé Palácio) e a Paramount (arrendatária do Capitólio e Império). Por fim, esses seis cinemas foram os responsáveis por estrear para a plateia carioca os primeiros filmes sonoros, todos exclusivamente norteamericanos e produzidos pelos Metro-Goldwyn-Mayer, Paramout, Fox, Universal, Warner e First National.

As principais informações sobre essa primeira fase estão resumidas na tabela abaixo:

\footnotetext{
${ }^{5}$ Os cinemas Capitólio, Glória e Império foram inaugurados em 1925, o cine Odeon em 1926, e o cine Pathé Palace em 1928. O Palácio Theatro era um cineteatro mais antigo, mas sofreu grande reforma no início de 1929, passando a funcionar exclusivamente como cinema.
} 


\begin{tabular}{|c|c|c|c|c|c|c|c|}
\hline \multicolumn{8}{|c|}{$1^{a}$ Fase da conversão das salas cariocas para o cinema sonoro ${ }^{6}$} \\
\hline $\begin{array}{l}\text { Nome do } \\
\text { Cinema }\end{array}$ & Categoria & Exibidor & $\begin{array}{c}\text { Lotaçã } \\
\text { o }\end{array}$ & $\begin{array}{l}\text { Rua, Bairro e/ou } \\
\text { Circunscrição } \\
\text { administrativa }\end{array}$ & $\begin{array}{l}\text { Filme exibido / estúdio } \\
\text { produtor / estreia ou não }\end{array}$ & $\begin{array}{c}\text { Modelo e } \\
\text { marca do } \\
\text { equipamento }\end{array}$ & Data \\
\hline $\begin{array}{l}\text { Palácio } \\
\text { Theatro }\end{array}$ & Extra & $\mathrm{CBC}$ & 1.900 & $\begin{array}{l}\text { Rua do Passeio, } 40 \\
\text { (Centro) }\end{array}$ & $\begin{array}{l}\text { A melodia da Broadway } \\
\text { (Metro) - estreia }\end{array}$ & $\begin{array}{l}\text { Western Electric } \\
\text { (conjugado) }\end{array}$ & $\begin{array}{c}20 / 06 / 192 \\
9\end{array}$ \\
\hline Odeon & Extra & $\mathrm{CBC}$ & 1.344 & $\begin{array}{l}\text { Praça Floriano, } 7 \text { - } \\
\text { Cinelândia (Centro) }\end{array}$ & $\begin{array}{c}\text { Follies de } 1929 \\
\text { (Fox) - estreia }\end{array}$ & $\begin{array}{l}\text { Western Electric } \\
\text { (conjugado) }\end{array}$ & $\begin{array}{c}22 / 07 / 192 \\
9 \\
\end{array}$ \\
\hline $\begin{array}{l}\text { Pathé } \\
\text { Palacio }\end{array}$ & $1^{\mathrm{a}}$ classe & $\begin{array}{l}\text { Marc Ferrez \& } \\
\text { Filhos }\end{array}$ & 918 & $\begin{array}{l}\text { Praça Floriano, } 45 \\
\text { Cinelândia (Centro) }\end{array}$ & $\begin{array}{c}\text { Boêmios } \\
\text { (Universal) - estreia }\end{array}$ & $\begin{array}{l}\text { Western Electric } \\
\text { (conjugado) }\end{array}$ & $\begin{array}{c}19 / 08 / 192 \\
9\end{array}$ \\
\hline Capitólio & Extra & Paramount & 955 & $\begin{array}{l}\text { Praça Floriano, } 51 \\
\text { Cinelândia (Centro) }\end{array}$ & $\begin{array}{c}\text { Marcha Nupcial } \\
\text { (Paramount) - estreia }\end{array}$ & $\begin{array}{l}\text { Western Electric } \\
\text { (conjugado) }\end{array}$ & $\begin{array}{c}06 / 09 / 192 \\
9 \\
\end{array}$ \\
\hline Glória & Extra & $\mathrm{CBC}$ & 1.063 & $\begin{array}{c}\text { Praça Floriano, 35/7 } \\
\text { Cinelândia (Centro) }\end{array}$ & $\begin{array}{l}\text { O homem e o momento } \\
\text { (First National) - estreia }\end{array}$ & $\begin{array}{l}\text { Western Electric } \\
\text { (conjugado) }\end{array}$ & $\begin{array}{c}27 / 09 / 192 \\
9\end{array}$ \\
\hline Império & $1^{\mathrm{a}}$ classe & Paramount & 526 & $\begin{array}{l}\text { Praça Floriano, } 19 \\
\text { Cinelândia (Centro) }\end{array}$ & $\begin{array}{c}\text { Canção do Lobo } \\
\text { (Paramount) - estreia }\end{array}$ & $\begin{array}{l}\text { Western Electric } \\
\text { (conjugado) }\end{array}$ & $\begin{array}{c}27 / 09 / 192 \\
9\end{array}$ \\
\hline
\end{tabular}

\section{Segunda fase: outubro de 1929 a dezembro de 1930.}

A partir de outubro de 1929, teria início uma segunda fase na conversão do circuito exibidor cinematográfico carioca à projeção de filmes sonoros. Em primeiro lugar, essa nova fase foi marcada pela expansão da conversão para outras localidades na cidade do Rio de Janeiro. Já em $1^{\circ}$ de outubro, o cinetheatro São José, principal cinema da Empresa Paschoal Segreto, localizado na Praça Tiradentes, tradicional reduto teatral da cidade, foi anunciado como o "primeiro cinema fora da Avenida a apresentar o cinema sonoro" (A NOITE, 1929,

${ }^{6}$ As informações sobre lotação, exibidor e endereço das salas foram retiradas, sobretudo, de Diretoria de Estatística Municipal (1938) e Alice Gonzaga (1996). As informações sobre os primeiros filmes sonoros exibidos, a data da estreia dos novos equipamentos sonoros e seu modelo e marca, foram obtidas em pesquisa em diversas edições publicadas em 1929 por jornais cariocas como Correio da Manhã, O Paíz e O Jornal, entre outros.

${ }^{7}$ A categoria da sala foi baseada na "classificação dos cinemas fornecida pelo Sindicato de Exibidores para efeito de tabela de aluguel dos complementos fornecidos pela Distribuidora de Filmes Brasileiros", datada de 1934 (In: CARIJÓ, 1937, p. 62). Embora seja uma classificação feita cinco anos após 1929 e que reflete mudanças ocorridas nesse período - o cine Capitólio, por exemplo, foi renomeado como cine Broadway -, ela serve como parâmetro aproximado para os fins desse artigo. 
p. 5). Isto é, o cinema sonoro saía do abrigo exclusivo da Avenida Rio Branco, antiga Avenida Central, e suas imediações, como a Rua do Passeio onde ficava o Palácio Theatro. A novidade começou, portanto, a chegar a cinemas localizados no centro do Rio de Janeiro, mas fora da então luxuosa e moderna Cinelândia - o também chamado "Quarteirão Serrador", nos arredores da Praça Floriano. Além do cine São José, ainda em outubro de 1929 foi inaugurada aparelhagem sonora no tradicional cine Ideal, localizado na Rua da Carioca, também no centro da cidade.

Mas nesse mesmo mês o cinema sonoro também ultrapassou a região central da cidade, onde ficavam as melhores salas, também chamadas de "cinemas lançadores". O cine Hélios, no Andaraí, após ser convertido para a projeção sonora, propagandeava ser "o único cinema de bairro que tem o verdadeiro cinema falado". (O JORNAL, 1929, p. 13). Se no Rio de Janeiro os talkies começavam a chegar aos bairros residenciais - os "cinemas de bairro" eram assim chamados por serem frequentados, sobretudo, pelos moradores da vizinhança -, a novidade também já tinha atravessado a Baía de Guanabara. Afinal, já em setembro de 1929 a Empresa Paschoal Segreto inaugurou a aparelhagem sonora do Cine-Theatro Imperial, o melhor cinema de Niterói, que se tornava a terceira cidade do país a possuir o cinema sonoro após São Paulo e Rio de Janeiro. (FREIRE, 2012b).

Nessa segunda fase, o ritmo de conversão do circuito exibidor permaneceu acelerado. Entre outubro e dezembro de 1929, mais dez salas de exibição cariocas foram convertidas para o cinema sonoro. Ao longo do ano de 1930, temos indicações de pelo menos outras dezoito salas adaptadas para as projeções de filmes sonoros no Rio de Janeiro.

As primeiras salas cariocas convertidas nessa segunda fase, embora não estivessem no mesmo nível dos palácios da Cinelândia, em termos de sofisticação, preço e conforto, eram os cinemas lançadores de outras cadeias exibidoras. Se na primeira fase, os seis cinemas adaptados pertenciam, como vimos, à $\mathrm{CBC}$, Marc Ferrez \& Filhos, e Paramount, nessa segunda fase tratavamse das melhores salas dos exibidores Luiz Severiano Ribeiro (Exibidores Reunidos 
Sociedade), Vital Ramos de Castro (Empresa V. R. Castro), Comendador Martinelli e Generoso Ponce (Empresa Brasileira de Cinemas) e Domingos Segreto (Empresa Paschoal Segreto).

Esses cinemas cobravam ingressos mais baratos que os da Cinelândia (o mais caro geralmente custava três mil réis) e serviram para exibir, em circuito secundário, os grandes lançamentos que já tinham sido projetados no Quarteirão Serrador com grande sucesso. Exibido em sessões lotadas, A melodia da Broadway, por exemplo, só teria saído de cartaz do Palácio Theatro por pressão da First National, que aguardava data para estrear A divina dama (The Divine Lady, Frank Lloyd, 1929), seu primeiro filme sonoro. Assim, o talkie da Metro, exibido entre junho e julho de 1929 na Cinelândia, ainda tinha grande potencial de público ao ser escolhido para estrear a aparelhagem sonora do cine Ideal, em 5 de outubro de 1929.

Da mesma forma, o cartaz da inauguração da projeção sonora do cine Fluminense, em São Cristovão, em 15 de novembro de 1929, era O Pagão (The Pagan, W.S. Van Dyke, 1929) também da Metro. O filme estrelado por Ramon Novarro havia estreado no Palácio Theatro em 5 de outubro, mas já tinha saído de cartaz cerca de um mês antes, mesmo desfrutando de boas bilheterias. O mesmo ocorreu com Hollywood Revue (Charles Reisner, 1929), estreia do cinema sonoro no cine Atlântico, em Copacabana, em dezembro de 1929, que fora lançado no mês anterior no Palácio Theatro. Ou seja, essa expansão do cinema sonoro permita que os primeiros e grandes sucessos do cinema sonoro na cidade pudessem ser exibidos em circuito. Isto é, serem programados em salas de segunda ou terceira linha após já terem cumprido suas carreiras iniciais nos cinemas lançadores, atingindo plateias de diferentes bairros e/ou classes sociais.

Outra opção para as salas convertidas nessa segunda fase foi estrear os primeiros filmes sonoros de estúdios norte-americanos independentes, que não possuíam agências distribuidoras próprias no Brasil, como os da Tiffany-Stahl Productions ou Cecil B DeMille Productions Inc. Esses filmes eram então lançados por distribuidoras brasileiras, tais como o Programa Serrador, o Programa V. R. de Castro ou o Programa Matarazzo. Havia ainda a possibilidade de estrear filmes de 
grandes estúdios norte-americanos que não tinham salas lançadoras próprias ou contratos exclusivos com os principais exibidores, como a Columbia ou United Artists.

$\mathrm{Se}$ os melhores cinemas do Rio, considerados da classe "Extra", se converteram todos ao sonoro na primeira fase, a partir de outubro de 1929 cinemas de $1^{\mathrm{a}}$ e $2^{\mathrm{a}}$ classe também se adaptaram, mas nem todos. Salas de exibição tradicionais como o cine Íris, na Rua da Carioca, e o cine Pathé (ou Pathézinho), na Avenida Rio Branco, não se adaptaram nem em 1929 ou mesmo em 1930, motivando críticas e elogios ao manterem-se exibindo exclusivamente filmes silenciosos. Já em agosto de 1929, por exemplo, o crítico de Fon-Fon! precisava alertar sobre a presença de um bom filme silencioso em cartaz na Cinelândia:

Esta novidade de filmes falados, sincronizados, cantados, dançados etc., está, além d'outras coisas, a praticar a injustiça de conceder uma vida obscura a filmes silenciosos que são belíssimos trabalhos. O público - a eterna criança - deixa-se conduzir cegamente por fantasias e esquece-se de quem the oferece boas impressões de arte. (FON-FON!, 1929, p. 65).

Quando o cine Íris lançou Febre de Broadway (Broadway Fever, Edward F. Cline, 1929), da Tiffany Stahl, o crítico de Selecta reforçou que "o cinema falado está privando o Quarteirão [Serrador] de alguns bons filmes silenciosos. Este é um deles". (SELECTA, 1929, p. 26). Por outro lado, o Pathezinho, localizado na Avenida Rio Branco, recebeu reprimendas na mesma revista por exibir Pancadas de amor (The Whip Woman, Joseph C. Boyle, 1928), da First National, filme velho que, segundo o crítico, "só a carência de filmes silenciosos, deu margem a vê-lo nas telas cariocas". (SELECTA, 1929, p. 26).

Se a oferta de cópias de novos filmes norte-americanos silenciosos de qualidade parecia se tornar cada vez mais restrita conforme o ano de 1929 ia chegando ao fim, havia ainda a alternativa dos filmes europeus. Essa era a estratégia do cine Rialto, na Avenida Rio Branco, que se manteve dedicado ao Programa Urânia, composto basicamente de filmes silenciosos alemães dos estúdios UFA. 
Abaixo está a tabela dos cinemas cariocas convertidos no início da segunda fase, entre outubro e dezembro de 1929:

\begin{tabular}{|c|c|c|c|c|c|c|c|}
\hline \multicolumn{8}{|c|}{$2^{a}$ Fase da conversão das salas cariocas para o cinema sonoro (out-dez. 1929) } \\
\hline $\begin{array}{l}\text { Nome do } \\
\text { Cinema }\end{array}$ & Categoria & Exibidor & Lotação & $\begin{array}{l}\text { Rua, Bairro e/ou } \\
\text { Circunscrição } \\
\text { administrativa } \\
\end{array}$ & $\begin{array}{l}\text { Filme exibido / estúdio } \\
\text { produtor / estreia ou não }\end{array}$ & $\begin{array}{c}\text { Modelo e } \\
\text { marca do } \\
\text { equipamento } \\
\end{array}$ & Data \\
\hline São José & $\mathrm{N} / \mathrm{A}$ & $\begin{array}{c}\text { Emp. } \\
\text { Paschoal } \\
\text { Segreto } \\
\end{array}$ & 1.718 & $\begin{array}{c}\text { Praça Tiradentes, 3/5 } \\
\text { (Centro) }\end{array}$ & $\begin{array}{c}\text { Marcha Nupcial } \\
\text { - já exibido } \\
\end{array}$ & $\begin{array}{l}\text { Western Electric } \\
\text { (conjugado) }\end{array}$ & $\begin{array}{c}01 / 10 / 192 \\
9 \\
\end{array}$ \\
\hline Ideal & $2^{a}$ classe & $\begin{array}{l}\text { Exibidores } \\
\text { Reunidos }\end{array}$ & 1.097 & $\begin{array}{c}\text { Rua da Carioca, 60/4 } \\
\text { (Centro) }\end{array}$ & $\begin{array}{c}\text { A melodia da Broadway } \\
\text { - já exibido }\end{array}$ & $\begin{array}{c}\mathrm{RCA}- \\
\text { (conjugado) }\end{array}$ & $\begin{array}{c}05 / 10 / 192 \\
9 \\
\end{array}$ \\
\hline Popular & $2^{\mathrm{a}}$ classe & $\begin{array}{l}\text { Emp. V. R. de } \\
\text { Castro }\end{array}$ & 1.300 & $\begin{array}{l}\text { Av. Marechal Floriano, } \\
97 / 103 \text { (Centro) }\end{array}$ & $\begin{array}{c}\text { O clube dos celibatários } \\
\text { (Oscar Price Productions) - } \\
\text { estreia }\end{array}$ & $\begin{array}{c}\text { Pacent - } \\
\text { (Vitaphone?) }\end{array}$ & $\begin{array}{c}23 / 09 / 192 \\
9\end{array}$ \\
\hline Hélios & $4^{\mathrm{a}}$ classe & $\begin{array}{c}\text { Emp. } \\
\text { Paschoal } \\
\text { Giorno } \\
\end{array}$ & 603 & $\begin{array}{c}\text { Rua Barão de } \\
\text { Mesquita, } 640 \text { (Andaraí) } \\
\end{array}$ & $\begin{array}{c}\text { O homem e o momento } \\
\text { - já exibido }\end{array}$ & $\begin{array}{c}\mathrm{RCA} \\
\text { (Vitaphone?) }\end{array}$ & $\begin{array}{c}07 / 10 / 192 \\
9 \\
\end{array}$ \\
\hline Mascote & $3^{a}$ classe & $\begin{array}{l}\text { Emp. V. R. de } \\
\text { Castro }\end{array}$ & 1.060 & $\begin{array}{c}\text { Rua Arquias Cordeiro, } \\
324 \text { (Méier) }\end{array}$ & $\begin{array}{c}\text { O submarino } \\
\text { (Columbia) - já exibido }\end{array}$ & $\begin{array}{c}\text { Pacent } \\
\text { (Vitaphone?) }\end{array}$ & $\begin{array}{c}01 / 11 / 192 \\
9 \\
\end{array}$ \\
\hline Paris & $3^{a}$ classe & $\begin{array}{c}\text { Emp. V. R. de } \\
\text { Castro }\end{array}$ & 518 & $\begin{array}{c}\text { Praça Tiradentes, } 42 \\
\text { (Centro) }\end{array}$ & $\begin{array}{c}\text { O uivar das feras } \\
\text { (Mascot Pictures) - já } \\
\text { exibido } \\
\end{array}$ & $\begin{array}{c}\text { Pacent } \\
\text { (Vitaphone?) }\end{array}$ & $\begin{array}{c}04 / 11 / 192 \\
9 \\
\end{array}$ \\
\hline Primor & $3^{\mathrm{a}}$ classe & $\begin{array}{l}\text { Emp. V. R. de } \\
\text { Castro }\end{array}$ & $\mathrm{N} / \mathrm{A}$ & $\begin{array}{c}\text { Avenida Passos, } 119 \\
\text { (Centro) }\end{array}$ & $\begin{array}{l}\text { O submarino } \\
\text { - já exibido }\end{array}$ & $\begin{array}{c}\text { Pacent } \\
\text { (Vitaphone?) }\end{array}$ & $\begin{array}{c}13 / 11 / 192 \\
9\end{array}$ \\
\hline $\begin{array}{c}\text { Fluminens } \\
\mathrm{e}\end{array}$ & $3^{a}$ classe & Camilo Gorga & 1.519 & $\begin{array}{l}\text { Av. Mar. Deodoro, 105, } \\
\text { São Cristóvão }\end{array}$ & $\begin{array}{c}\text { O Pagão } \\
\text { (Metro) - já exibido }\end{array}$ & $\begin{array}{c}\text { Pacent } \\
\text { (conjugado?) }\end{array}$ & $\begin{array}{c}15 / 11 / 192 \\
9\end{array}$ \\
\hline Eldorado & $1^{\mathrm{a}}$ classe & $\begin{array}{c}\text { EBC } \\
\text { (Martinelli e } \\
\text { Ponce) }\end{array}$ & 1.078 & $\begin{array}{l}\text { Av. Rio Branco, 166/8 } \\
\text { (Centro) }\end{array}$ & $\begin{array}{c}\text { A mulher sem Deus } \\
\text { (C.B. DeMille Production) - } \\
\text { estreia }\end{array}$ & $\begin{array}{c}\mathrm{RCA} \text { - } \\
\text { (conjugado) }\end{array}$ & $\begin{array}{c}18 / 11 / 192 \\
9\end{array}$ \\
\hline Atlântica & $2^{\mathrm{a}}$ classe & $\begin{array}{l}\text { Exibidores } \\
\text { Reunidos }\end{array}$ & 986 & $\begin{array}{c}\text { Rua Copacabana, } 610, \\
\text { Copacabana }\end{array}$ & $\begin{array}{l}\text { Hollywood Revue } \\
\text { (Metro) - já exibido }\end{array}$ & $\begin{array}{c}\text { RCA - } \\
\text { (conjugado) }\end{array}$ & $\begin{array}{c}20 / 12 / 192 \\
9 \sim\end{array}$ \\
\hline
\end{tabular}

Se destacamos acima apenas as salas adaptadas no início da segunda fase, devemos ressaltar que o ritmo de conversão e expansão do cinema sonoro no Rio de Janeiro prosseguiu em ritmo acelerado nos primeiros meses de 1930. Luiz Severiano Ribeiro, por exemplo, depois do cine Ideal e o do Atlântico, vai aparelhar, entre janeiro e março de 1930, três outras salas. Em apenas três meses, o cinema sonoro é inaugurado no cine Velo (na Tijuca), no cine Vila Isabel (no

\footnotetext{
${ }^{8}$ Novamente utilizamos as informações de 1934 (CARIJÓ, 1937, p. 62), o que traz problemas como o fato do cineteatro São José, àquela altura, ter voltado a funcionar exclusivamente como teatro e não constar mais na listagem.
} 
bairro de mesmo nome) e no cine Brasil (também na Tijuca). Até o final de 1930, o Exibidores Reunidos converteria ainda outras salas como o cine Modelo (Riachuelo), cine Guanabara (Botafogo) e cine América (Tijuca), conseguindo atingir o público de diferentes bairros da cidade, da Zona Sul à Zona Norte.

Além da expansão geográfica, outro dado importante dessa segunda fase é que ela foi marcada pelo "jeitinho" dado por alguns exibidores de menor porte para tentarem embarcar na "febre do sincronizado" que continuava atingindo a cidade. A principal tentativa de adaptação experimentada foi a instalação de tocadiscos comuns nas cabines de projeção, com o objetivo de executar discos fonográficos em acompanhamento aos filmes. Nesses casos, eram tocados discos de $78 \mathrm{rpm}$, com duração de cerca de 3 minutos, ao invés dos discos especiais do Vitaphone, de maior dimensão e velocidade de $331 / 3 \mathrm{rpm}$, que tinham até 11 minutos de duração.

O cine-theatro Phenix, localizado na Avenida Almirante Barroso, foi uma das salas que apelaram para esse tipo de expediente, utilizando um toca-discos Victor para sincronizar o filme europeu silencioso Volga Volga (Wolga Wolga, Viktor Tourjansky, 1928), em cartaz a partir de 13 de setembro de 1929. O famoso sistema Sincrocinex, criado para permitir a exibição do primeiro longa-metragem sincronizado brasileiro, Acabaram-se os otários (Luiz de Barros, 1929), também era baseado no mesmo princípio, tendo sido instalado especialmente para a exibição desse filme no cine Rialto, a partir de 26 de setembro de 1929.

Vários cinemas de bairro cariocas - como o cine Guarany, no Estácio, ou o cine Polytheama, no Largo do Machado - apelaram da mesma forma para esse "sincronismo improvisado" no segundo semestre de 1929. Método descrito como uma forma de tapear o público, os aparelhos toca-discos conjugados a projetores silenciosos começaram a ser apelidados pela imprensa de "tapeafones". Esse engodo, vendido como "cinema sincronizado", oferecia uma projeção meramente acompanhada por música e às vezes efeitos sonoros (através de "discos de ruídos") executados por meios mecânicos. Apenas os projetores sonoros, porém, eram em geral utilizados para apresentar filmes cantados ou falados, nos quais um sincronismo preciso era supostamente imprescindível. Por isso a ressalva na 
já citada publicidade do cine Hélios, ao instalar equipamentos de projeção Vitaphone e Movietone, de se intitular "o único cinema de bairro que tem o verdadeiro cinema falado" (grifo nosso).

Entre Vitaphones e "Tapeafones", quem saiu perdendo foram os músicos dos cinemas cariocas. Ao longo de poucos meses eles foram sendo demitidos tanto das mais luxuosas salas de exibição que instalaram os novos equipamentos sonoros, quanto por exibidores que substituíam suas "orquestrinhas" por potentes toca-discos. Essas adaptações mais baratas que tentavam concorrer com a moda dos filmes sonoros resultaram no súbito e crescente desemprego de muitos músicos que passaram a viver uma "situação trágica", como noticiou a imprensa. Já em outubro de 1929, nos arredores da Avenida Rio Branco só restavam dois cinemas com orquestras que tocavam ao vivo: o Rialto e o Pathé (ou Pathezinho). Todos os demais estavam "victrolizados", relatava o jornal O Globo (1929, p. 5). No mês seguinte, em longo artigo no Jornal do Commercio, outro crítico também se indignava com a situação: "É absolutamente inadmissível, a pretexto de se tratar de fita 'sincronizada' ou 'sonora', substituir a orquestra de músicos nacionais (que dá outro colorido e vida ao filme) por uma sequência de discos fonográficos". (GUIMARÃES, 1929).

Por mais que as orquestras dos cinemas fossem tradicionalmente criticadas pelo público e imprensa (PEREIRA, 2014; SOUZA, 2014b), não faltou quem lamentasse sua rápida extinção nas grandes cidades. A substituição dos músicos por toca-discos em salas do Rio e São Paulo chegou a motivar manifestações de artistas e intelectuais como Heitor Villa-Lobos ou Mário de Andrade. O maestro, por exemplo, deu entrevista lamentando como "o Rio está gramofonizado, horrivelmente gramofonizado..." Solidarizando-se com seus colegas, Villa-Lobos apontava para "um negro quadro que se desenha em frente aos nossos músicos de orquestra, que já estão ficando inteiramente abandonados por causa dos filmes que cantam, dançam e tocam os sete instrumentos da civilização moderna". (O GLOBO, 1929, p. 1-2).

Escrevendo sobre os cinemas de São Paulo, em artigo do Diário Nacional de 15 de janeiro de 1930, o escritor Mário de Andrade também criticou a substituição 
das orquestras por toca-discos nos cinemas:

\begin{abstract}
A sessão abre. De primeiro eram orquestrinhas detestáveis que tocavam no geral sempre a mesma marchinha ou dobrado de abertura. A peça era detestável, convenho, e detestavelmente executada. Mas era orquestrinha. Cousa característica dos ambientes de divertimento pra fora do lar. A gente se ambientava muito bem. Olhava as fitas e na maioria das vezes esquecia a orquestrinha. [...] Eu admito que certas peças sincronizadas ganham bem musicalmente com a sincronização vinda com elas e não são essas fitas que ataco. Mas acho censurável e ataco é os mitras de donos de cinema que por causa disso dispensam as orquestras e agora, à guisa de música de cinema, nos impingem discos e mais discos que a gente acabou de escutar em casa mesmo. Isso é que é detestável e não pode continuar assim. 0 cinema sincronizado não dispensa as orquestras no lugar. Cada macaco no seu galho. (CUNHA, 2010, p. 42-4).
\end{abstract}

Apesar desses protestos, a "marcha do progresso" não diminuiu. Em meados de 1930, com a rápida e contínua dispensa dos músicos das salas de cinema, as "orquestrinhas" já despertavam nostalgia em cinéfilos cariocas. Isso pode ser verificado na crítica ao que seria um bom filme silencioso - solitário em meio à "invasão dos talkies" - que havia sido exibido numa das poucas salas ainda não convertidas no centro da cidade: "O Íris, neste particular, é o tipo de cinema que desperta saudades. A pianista com a xícara de café e o copo d'água ao lado. A flauta. A clarineta. Uma orquestra! Incrivel..." (CINEARTE, 1930, p. 31). Entretanto, em mais alguns meses praticamente não restaria mais nenhum cinema do Rio de Janeiro que já não estivesse convertido para a projeção sonora ou, pelo menos, "vitrolizado".

Ainda em relação aos equipamentos de projeção de imagem e som, outra característica fundamental dessa segunda fase de conversão dos cinemas cariocas é o fato dos exibidores que instalaram projetores sonoros (e não tocadiscos) terem optado, ainda assim, por equipamentos mais baratos e com melhores condições de pagamento do que os da Western Electric. A empresa norte-americana foi acusada, inclusive, de tentar impor um monopólio na venda da aparelhagem sonora para os exibidores brasileiros. Nesse sentido, as melhores salas de um circuito secundário convertido nessa segunda fase optaram pela 
compra e instalação do Photophone, equipamento de som ótico da Radio Corporation of America (RCA), também importado dos EUA. Tendo baixado seus preços em maio de 1929, a RCA tentava, em todo o mundo, alcançar a Western Electric, que saíra na dianteira no mercado de venda de projetores e equipamentos sonoros para as salas de cinema. A estratégia funcionou e, nos Estados Unidos, a RCA aumentou em 200\% suas instalações entre 1930 e 1931. (CRAFTON, 1997, p. 161, 164). No Brasil, a RCA também iniciou uma estratégia agressiva para tentar concorrer com a Western, o que incluiu, por exemplo, ceder gratuitamente aparelhagem sonora para o cine Atlântico, como forma de demonstrar publicamente a qualidade de seus equipamentos. (GONZAGA, 1996, p. 164, 194).

Por outro lado, mantendo-se como sinônimo de qualidade, a Western Electric permaneceu sendo a escolha de salas como o cine Guanabara, localizado na Praia de Botafogo, que fez questão de destacar em sua publicidade ter sido "adaptado com os modernos aparelhos da Western Electric Company". (CINE GUANABARA, 1930, grifo do texto). Conforme Crafton (1997, p. 164), houve uma oposição, mas não uma guerra entre a Western e a RCA pelo mercado exibidor: "os lucros eram grandes o suficiente para serem compartilhados".

Uma alternativa ainda mais barata que a Western e mesmo a RCA eram os equipamentos da empresa norte-americana Pacent. Estes saíam ainda mais em conta caso o projetor fosse dotado apenas de projeção em discos (Vitaphone), que alguns exibidores brasileiros acreditavam ser um sistema mais confiável do que a então recente e pouco conhecida tecnologia de som ótico.

A partir de 1930, a principal opção para os exibidores menos capitalizados passaram a ser os primeiros projetores sonoros nacionais comercializados no Rio de Janeiro. O projetor Cinephon, modelo Vitaphone, da empresa de José. J. de Barros foi usado pela primeira vez no cine Velo, no início de 1930, o terceiro cinema de Severiano Ribeiro a ser sonorizado. Após duas instalações RCA (cine Ideal e cine Atlântico), o exibidor cearense apostava num projetor nacional mais

\footnotetext{
9 "The profits were vast enough to share". (tradução do autor).
} 
barato.

O preço fazia muita diferença, ao que parece. Ao final de 1930 , onze cinemas cariocas tinham instalado os projetores nacionais da marca Cinephon, com o cinema sonoro atingindo bairros como Jacarepaguá (cine Ipiranga), Bonsucesso (cine Paraíso), Méier (cine Méier), Madureira (cine Alpha) e Grajaú (cine Grajaú). (CINEPHON, 1930).

Em 1930, ainda, o Rio de Janeiro conheceu seus primeiros filmes sonoros estrangeiros de outras nacionalidades para além dos norte-americanos. Filmes cantados e falados em alemão, espanhol e francês foram exibidos pela primeira vez para os cariocas. Coerente com sua programação, o cine Rialto também se diferenciou na nacionalidade dos seus equipamentos sonoros. Em 28 de julho de 1930, a sala de exibição inaugurou sua instalação alemã da marca Ufaton.

Além do cinema sonoro atingir, nessa segunda fase, uma variedade maior de bairros, exibindo filmes sonoros de diferentes produtoras e países, os tipos de salas de exibição convertidas também são mais diversos. Sobretudo ao longo de 1930 , foram de fato convertidos para a nova tecnologia alguns cineminhas de bairro. Eram salas de exibição tidas como de $2^{a}, 3^{a}$ e até $4^{a}$ categoria, e que exibiam filmes semanas e até meses após eles estrearem nos cinemas lançadores da Cinelândia. O cine Apollo, localizada no Rio Comprido, estreou sua aparelhagem sonora em 24 de abril de 1930 com o filme Follies de 1929. Esse filme estreara no cine Odeon em julho de 1929, isto é, nove meses antes. Pode-se imaginar o estado daquela cópia $35 \mathrm{~mm}$ ao ser exibida no Apollo, provavelmente já danificada com muitos riscos e sujeira decorrentes de tantas projeções.

Alguns dos cinemas convertidos nessa segunda fase também consistiam em salas mais antigas, antiquadas em sua arquitetura e inadequadas em sua acústica, construídas ainda na década de 1910 ou início dos anos 1920. Eram salas já tradicionais como as da região da Tijuca e adjacências, como o cine Velo, cine Boulevard ou o cine Modelo. Podemos citar ainda o cine América, na Praça Saens Peña, inaugurado em $1918 \mathrm{com}$ arrojado projeto do arquiteto Antonio Virzi. Apesar de convertido para o cinema sonoro em 1930, a sala de exibição seria logo demolida e reconstruída. 
Outros desses cinemas de bairro convertidos também nessa segunda fase eram, porém, salas recentes, construídas ou reformadas como parte do movimento de expansão e consolidação do circuito de exibidores, como o já mencionado Severiano Ribeiro, mas também Domingos Vassalo Caruso ou Antonio Mendes Monteiro, cujos investimentos concentraram-se nos bairros proletários. Caruso, por exemplo, era proprietário do cine Paraíso, em Bonsucesso, inaugurado em 1928 com 1.500 lugares e convertido logo em abril de 1930; enquanto Monteiro estava à frente do cine Alfa, em Madureira, inaugurado em 1929 e convertido no ano seguinte. Como apontou Alice Gonzaga (1996, p. 142-4), eram cinemas amplos que viram a ser chamados de "cabeças de circuito", pertencentes a exibidores que exploravam o comércio cinematográfico no subúrbio carioca.

Fossem salas maiores ou menores, modernas ou antiquadas, em comum havia o fato de que a adaptação de salas de exibição cariocas para o cinema sonoro foi deixando de ser, ao longo de 1930, algo que merecesse destaque na grande imprensa carioca. Desse modo, como essa pesquisa baseou-se, em grande parte, na pesquisa em jornais de grande circulação (O Paiz, Correio da Manhã, O Jornal, entre outros), obter informações sobre a conversão tardia de salas cariocas fica cada vez mais difícil. Afinal, conforme a projeção de filmes sonoros tornava-se mais comum, deixando de ser uma novidade, a adaptação "atrasada" de alguns cinemas não merecia notícia nos jornais, pois seu interesse era, sobretudo, para o bairro ou localidade específica. De todo modo, apesar da escassez de informações, foi possível elaborar a tabela abaixo que, diferentemente das anteriores, não é completa nem exaustiva. 


\begin{tabular}{|c|c|c|c|c|c|c|c|}
\hline \multicolumn{8}{|c|}{$2^{a}$ Fase da conversão das salas cariocas para o cinema sonoro (jan-dez. 1930) } \\
\hline $\begin{array}{c}\text { Nome do } \\
\text { Cinema }\end{array}$ & Categoria & Exibidor & Lotação & $\begin{array}{c}\text { Rua, Bairro e/ou } \\
\text { Circunscrição } \\
\text { administrativa }\end{array}$ & $\begin{array}{c}\text { Filme exibido / estúdio } \\
\text { produtor / estreia ou } \\
\text { não }\end{array}$ & $\begin{array}{c}\text { Modelo e } \\
\text { marca do } \\
\text { equipamento } \\
\end{array}$ & Data \\
\hline Velo & $3^{\mathrm{a}}$ classe & $\begin{array}{l}\text { Exibidores } \\
\text { Reunidos }\end{array}$ & 800 & $\begin{array}{l}\text { Rua Haddock Lobo, } \\
188 \text { (Rio Comprido) }\end{array}$ & $\begin{array}{c}\text { Hollywood Revue (Metro) } \\
\text { - já estreado }\end{array}$ & $\begin{array}{c}\text { Cinephon } \\
\text { (Vitaphone) }\end{array}$ & $\begin{array}{c}23 / 01 / 193 \\
0 \\
\end{array}$ \\
\hline Villa Isabel & $\mathrm{N} / \mathrm{A}$ & $\begin{array}{l}\text { Exibidores } \\
\text { Reunidos }\end{array}$ & 1063 & $\begin{array}{l}\text { Av. } 28 \text { de Setembro, } \\
425 \text { (Vila Isabel) }\end{array}$ & $\mathrm{N} / \mathrm{A}$ & $\begin{array}{l}\text { Cinephon } \\
\text { (Vitaphone) }\end{array}$ & $? / 03 / 1930$ \\
\hline Meyer & $4^{\mathrm{a}}$ classe & $\begin{array}{l}\text { Reis Amorim e } \\
\text { Cia }\end{array}$ & 627 & $\begin{array}{c}\text { Av. Amaro Cavalcanti, } \\
33 \text { (Méier) }\end{array}$ & $\begin{array}{c}\text { Hollywood Revue (Metro) } \\
\text { - já estreado }\end{array}$ & $\begin{array}{c}\text { Cinephon } \\
\text { (Vitaphone) }\end{array}$ & $\begin{array}{c}19 / 03 / 193 \\
0 \\
\end{array}$ \\
\hline Brasil & $\mathrm{N} / \mathrm{A}$ & $\begin{array}{c}\text { Exibidores } \\
\text { Reunidos } \\
\end{array}$ & 872 & $\begin{array}{l}\text { Rua Haddock Lobo, } \\
437 \text { (Rio Comprido) } \\
\end{array}$ & $\begin{array}{c}\text { Asas (Paramount) - já } \\
\text { estreado }\end{array}$ & $\begin{array}{l}\text { Cinephon } \\
\text { (Vitaphone) }\end{array}$ & $\begin{array}{c}10 / 04 / 193 \\
0 \\
\end{array}$ \\
\hline Paraíso & $\mathrm{N} / \mathrm{A}$ & D. V. Caruso & 1.500 & $\begin{array}{l}\text { Praça das Nações, } 66 \\
\text { (Bonsucesso) }\end{array}$ & $\begin{array}{c}\text { Hollywood Revue (Metro) } \\
\text { - já estreado }\end{array}$ & $\begin{array}{l}\text { Cinephon } \\
\text { (Vitaphone) }\end{array}$ & $\begin{array}{c}24 / 04 / 193 \\
0\end{array}$ \\
\hline Apollo & $4^{\mathrm{a}}$ classe & $\begin{array}{c}\text { Paschoal Giorno } \\
\& \text { Cia }\end{array}$ & 405 & $\begin{array}{c}\text { Praça Condessa de } \\
\text { Frontin, } 32 \\
\text { (Rio Comprido) }\end{array}$ & $\begin{array}{c}\text { Follies de } 1929 \text { (Fox) - já } \\
\text { estreado }\end{array}$ & $\mathrm{RCA}$ & $\begin{array}{c}24 / 04 / 193 \\
0 \\
\end{array}$ \\
\hline Real & N/A & $\begin{array}{l}\text { Empr. Fernando } \\
\text { Trogoletto }\end{array}$ & 530 & $\begin{array}{l}\text { Rua do Bom Retiro, } 250 \\
\text { (Engenho Novo) }\end{array}$ & $\begin{array}{c}\text { A Arca de Noé (Warner) - } \\
\text { já estreado }\end{array}$ & Mellaphone & $\begin{array}{c}15 / 05 / 193 \\
0 \\
\end{array}$ \\
\hline Ypiranga & N/A & $\begin{array}{c}\text { Elysio Alves } \\
\text { Neves }\end{array}$ & 600 & $\begin{array}{c}\text { Barão da Taquara, } 51 \\
\text { (Jacarepaguá) }\end{array}$ & $\begin{array}{c}\text { Paris (Warner) - já } \\
\text { estreado }\end{array}$ & Cinephon & $5 / 06 / 1930$ \\
\hline Modelo & $\mathrm{N} / \mathrm{A}$ & $\begin{array}{c}\text { Antônio Pinto da } \\
\text { Rocha }\end{array}$ & 924 & $\begin{array}{c}24 \text { de Maio, } 437 / 9 \\
\text { (Riachuelo) }\end{array}$ & N/A & $\begin{array}{c}\text { Cinephon } \\
\text { (Vitaphone) }\end{array}$ & $? / 05 / 1930$ \\
\hline $\begin{array}{l}\text { Engenho } \\
\text { de Dentro }\end{array}$ & $3^{a}$ classe & $\begin{array}{c}\text { Joaquim } \\
\text { Machado } \\
\end{array}$ & 1.000 & $\begin{array}{l}\text { Rua Engenho de } \\
\text { Dentro, } 50 \text { (Méier) }\end{array}$ & $\begin{array}{c}\text { Hollywood Revue (Metro) } \\
\text { - já estreado }\end{array}$ & $\mathrm{N} / \mathrm{A}$ & $\begin{array}{c}05 / 06 / 193 \\
0 \\
\end{array}$ \\
\hline Boulevard & $\mathrm{N} / \mathrm{A}$ & $\begin{array}{l}\text { M. G. Costa, } \\
\text { José Lourenço } \\
\text { de Oliveira }\end{array}$ & $\mathrm{N} / \mathrm{A}$ & $\begin{array}{c}\text { Av. } 28 \text { de Setembro, } \\
163 \text { (Vila Isabel) }\end{array}$ & $\begin{array}{c}\text { Broadway (Universal) - já } \\
\text { estreado }\end{array}$ & $\mathrm{N} / \mathrm{A}$ & $\begin{array}{c}13 / 07 / 193 \\
0\end{array}$ \\
\hline Nacional & $\mathrm{N} / \mathrm{A}$ & $\begin{array}{l}\text { Emp. Paschoal } \\
\text { Chrispim }\end{array}$ & 602 & $\begin{array}{l}\text { Rua Voluntários da } \\
\text { Pátria, 331-335 } \\
\text { (Botafogo) }\end{array}$ & $\begin{array}{l}\text { Um sonho que viveu (Fox) } \\
\text { - já estreado }\end{array}$ & Western Electric & $\begin{array}{c}25 / 07 / 193 \\
0 \quad 0\end{array}$ \\
\hline Rialto & $1^{\mathrm{a}}$ classe & $\begin{array}{l}\text { Exibidores } \\
\text { Reunidos }\end{array}$ & 494 & $\begin{array}{l}\text { Rua Senador Dantas, } \\
43 \text { (Centro) }\end{array}$ & Monolesco (UFA) - estreia & Ufaton & $\begin{array}{c}28 / 07 / 193 \\
0\end{array}$ \\
\hline Alpha & N/A & $\begin{array}{c}\text { [José Joaquim] } \\
\text { Pereira e Moreno }\end{array}$ & 1200 & $\begin{array}{c}\text { Est. Marechal, Rangel, } \\
19 \text { (Realengo) } \\
\text { Madureira } \\
\end{array}$ & $\mathrm{N} / \mathrm{A}$ & Cinephon & $\frac{O}{\frac{I}{Z}}$ \\
\hline $\begin{array}{c}\text { Guanabar } \\
\text { a }\end{array}$ & $2^{a}$ classe & $\begin{array}{l}\text { Exibidores } \\
\text { Reunidos }\end{array}$ & 1.770 & $\begin{array}{c}\text { Praia de Botafogo, } 506 \\
\text { (Botafogo) }\end{array}$ & $\mathrm{N} / \mathrm{A}$ & Western Electric & $? / 07 / 1930$ \\
\hline América & $2^{\mathrm{a}}$ classe & $\begin{array}{l}\text { Exibidores } \\
\text { Reunidos }\end{array}$ & 1.157 & $\begin{array}{c}\text { Rua Conde de Bonfim, } \\
334 \text { (Tijuca) }\end{array}$ & $\mathrm{N} / \mathrm{A}$ & $\mathrm{N} / \mathrm{A}$ & $? / 06 / 19 \frac{\Upsilon}{\bar{a}}$ \\
\hline Grajaú & $\mathrm{N} / \mathrm{A}$ & Paschoal Giorno & 270 & $\begin{array}{c}\text { Rua Barão de } \\
\text { Mesquita, } 972 \text { (Grajaú) }\end{array}$ & Valsa do amor (UFA) & Cinephon & $? / ? / 1930$ \\
\hline $\begin{array}{c}\text { Rio } \\
\text { Branco }\end{array}$ & N/A & $\begin{array}{c}\text { Luís Gonçalves } \\
\text { Ribeiro }\end{array}$ & 783 & $\begin{array}{l}\text { Senador Euzébio, } \\
188 / 190 \text { (Centro) }\end{array}$ & $\mathrm{N} / \mathrm{A}$ & Cinephon & ?/?/1930 \\
\hline
\end{tabular}

\section{Conclusão}

Se apontamos que a segunda fase de conversão para o cinema sonoro se iniciou em outubro de 1929, é mais difícil determinarmos quando ela se encerrou 
precisamente. Acreditamos que dezembro de 1930 pode ser tomado como um limite adequado devido a uma série de questões mais amplas e outras mais específicas. Em primeiro lugar, o golpe de Estado, com a tomada do poder pelos militares liderados por Getúlio Vargas, em 24 de outubro, vai ser o clímax de um período de extrema turbulência para o Brasil, especialmente para o Rio de Janeiro, obviamente afetando a frequência às salas de cinema.

Poucos dias antes da tomada de poder que daria fim à chamada República Velha, o jornal governista $O$ Paiz (incendiado após o golpe) comentava sobre os efeitos da crise política e econômica no comércio de diversões. Apesar de falar especificamente da indústria fonográfica, com a quase paralisação da venda de discos, certamente algo semelhante também poderia ser dito das salas de cinema:

\footnotetext{
O atual momento político que o país atravessa faz concentrar nos assuntos a ele pertinente toda a atenção dos seus habitantes, forçados, destarte, a abandorarem as suas recreações costumeiras e criando para o seu espírito um ambiente de trágicas elucubrações. Sofre com isso todo o comércio da Nação, mormente o que se relaciona com artigos não essenciais à vida material do homem. A fonografia, sem dúvida alguma, uma de suas formas de recreação mais preferidas pelo nosso público, não poderia deixar de sofrer as consequencias da agravação da crise por que temos passado desde o princípio do ano. (O PAIZ, 1930, p. 6).
}

A crise econômica, além de possivelmente refrear a frequência aos cinemas, teve um grande impacto no câmbio, desvalorizando a moeda brasileira e afetando o comércio do Brasil com os Estados Unidos, inclusive o cinematográfico. Se o preço de aluguel das cópias sonoras já tinha subido, a valorização do dólar pressionou ainda mais os custos que os distribuidores deveriam repassar para os exibidores locais. Da mesma forma, a importação de equipamentos sonoros dos Estados Unidos obviamente também se tornou muito mais dispendiosa.

Além disso, conforme a "febre do sincronizado" começava a passar, tornavamse mais evidentes as dificuldades para os filmes sonoros - especialmente os cada vez mais frequentes filmes inteiramente dialogados em inglês - substituírem definitivamente os filmes silenciosos como padrão de exibição no dia a dia do 
público e dos exibidores. O polêmico e complexo "problema linguístico" não tinha ainda encontrado uma solução definitiva, com diversas experiências sendo colocadas em prática ao longo de 1930 (legendagem, filmes falados em espanhol, cópias mudas etc.), mas sem encontrar uma resolução plenamente satisfatória para todas as plateias ainda naquele momento.

O final do ano, com o início do verão, era tradicionalmente considerado a pior época para as bilheterias dos cinemas, quando o público trocava as abafadas salas de cinema pela ida à praia, pela viagem para Petrópolis ou por outras diversões ao ar livre. Se o inverno de 1930 já tinha sido "curto e quente", com o calor retornando logo no início de outubro (O PAIZ, 1930, p. 1), os exibidores tinham motivos de preocupação com a chegada da nova estação.

Assim, no editorial do último número do ano de Cinearte, o editor da revista relatou uma conversa com exibidor Francisco Serrador sobre "a quadra que vamos atravessando, má em todos os sentidos, mas que se tem feito particularmente sentir no meio cinematográfico". Contestando os comentários de que os grandes cinemas cariocas colhiam lucros fabulosos, Serrador falava das enormes despesas decorrentes da adaptação para o cinema sonoro e das recorrentes flutuações do mercado, fosse por conta das estações do ano ou pela inconstância da qualidade dos filmes exibidos. Apesar de afirmar jamais desistir e revelar sua esperança num futuro melhor, o exibidor confessava:

E, contudo, posso hoje dizer-Ihe que creio jamais passou o nosso comércio por crise semelhante à que o aflige. O público já não é tão numeroso, devido aos motivos que todos sabem; a situação para muitos exibidores já é de angustia. Teremos de desanimar agora? (CINEARTE, 1930, p. 3).

Nos meses seguintes, a situação parece ter continuado a ser agravar ao ponto do jornalista Pedro Lima, dali a um ano, iniciar uma enquete sobre o mercado cinematográfico no Brasil para jornal carioca Diária da Noite com o dramático título: "Fecharão todos os cinemas do Brasil?" (SOUZA, 2014a; GONZAGA, 1996, p. 164-5).

Acreditamos, portanto, que a segunda fase da conversão para o cinema 
sonoro no Rio de Janeiro encerra, ao final de 1930, o período inicial de otimismo na chegada e expansão da nova tecnologia às salas de exibição cariocas. A fase seguinte, de janeiro de 1931 em diante, seria marcada por muito mais apreensão e indefinição.

Por fim, acreditamos que o presente estudo pode auxiliar outras pesquisas sobre o processo de conversão para o cinema sonoro em diferentes partes do Brasil, mas fazendo o alerta de que o caso do Rio de Janeiro, então Capital Federal e principal praça cinematográfica do país, talvez possa ter sido mais a exceção do que a regra em relação ao que ocorreu na maior parte das cidades brasileiras.

\section{Referências}

ALLEN, Robert C.; GOMERY, Douglas. Film History: Theory and Practice. New York: Knopf, 1985.

ALTMAN, Charles F. [Rick]. "Towards a historiography of American film". Cinema Journal, n. 16, v. 2, 1977.

CUNHA, Paulo José da Silva (org.). Mário de Andrade no Cinema. Rio de Janeiro: Nova Fronteira, 2010.

CARIJÓ, Armando Moura (relator). Associação Cinematográfica de Produtores Brasileiros: Relatório da Diretoria: Biênio de 2-6-34 a 2-6-36. Rio de Janeiro: Associação Cinematográfica de Produtores Brasileiros, 1937.

CINE GUANABARA. Programa, Rio de Janeiro, 30 de julho de 1930 (Arquivo Geral da Cidade do Rio de Janeiro).

CINEPHON. Catálogo. Rio de Janeiro: Gráfica Real Grandeza, s.d. [dez. 1930] (Arquivo Geral da Cidade do Rio de Janeiro).

CRAFTON, Donald. The Talkies: American Cinema's Transition to Sound, 19261931. Berkeley: University of California Press, 1997.

DIRETORIA DE ESTATíSTICA MUNICIPAL. Anuário Estatístico do Distrito Federal. Rio de Janeiro: Instituto Brasileiro de Geografia e Estatística (IBGE), 1938.

ELSAESSER, Thomas. "The New Film History". Sight and Sound, outono 1986. 
FREIRE, Rafael de Luna. "A febre dos sincronizados: os primeiros meses da exibição de filmes sonoros no Rio e em São Paulo em 1929". In: SOUZA, G. et al (Orgs.). XIII Estudos de Cinema e Audiovisual Socine. São Paulo: Socine, 2012a. 2. v.

FREIRE, Rafael de Luna. Cinematographo em Nictheroy: história das salas de cinema de Niterói. Niterói: Niterói Livros, 2012b.

GONZAGA, Alice. Palácios e poeiras: 100 anos de cinemas no Rio de Janeiro. Rio de Janeiro: Record, 1996.

GUIMARÃES, Arthur. "A evolução do cinematógrafo". Jornal do Commercio, 23 de novembro de 1929.

PEREIRA, Carlos Eduardo. A música no cinema silencioso no Brasil. Rio de Janeiro: Museu de Arte Moderna, 2014,

SOUZA, Carlos Roberto de. "Fecharão todos os cinemas do Brasil? (enquete de Pedro Lima em 1931)". Comunicação apresentada ao XVIII ENCONTRO SOCINE, Fortaleza, 2014a.

SOUZA, Carlos Roberto de. "Orquestras e vitrolas no acompanhamento do espetáculo cinematográfico silencioso brasileiro: o caso do cinema Triângulo, um saco de pancadas exemplar". Rebeca, v. 6, n. 6, 2014b.

\section{Artigos de jornais citados:}

A Noite, 1 de outubro de 1929, p. 5.

Cinearte, n. 229, 15 de julho de 1930, p. 31.

Cinearte, n. 253, 31 de dezembro de 1930, p. 3.

Fon-Fon!, 24 de agosto de 1929, p. 65.

O Globo, 20 de agosto de 1929, p. 1-2.

O Globo, 21 de outubro de 1929, p. 5.

O Jornal, 20 de outubro de 1929, p. 13.

O Paiz, 19 de outubro de 1930, p. 6.

O Paiz, 5 de outubro de 1930, p. 1. 


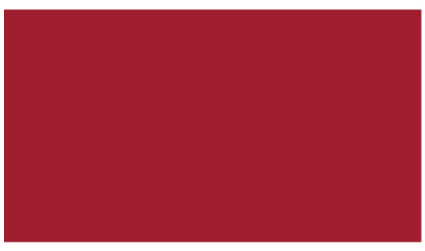

rebeca

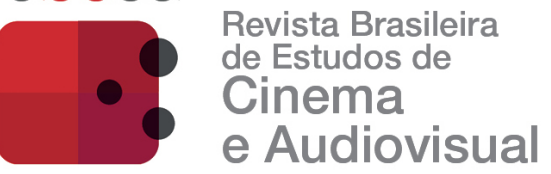

Selecta, 11 de dezembro de 1929, p. 26.

Selecta, 20 de novembro de 1929, p. 26. 